\title{
Perceived self-efficacy of students in a business simulation game
}

Research Article

\author{
Vinod Dumblekar* and Upinder Dhar \\ MANTIS, New Delhi, India \\ Shri Vaishnav Vidyapeeth Vishwavidyalaya, Indore, India
}

\begin{abstract}
Self-efficacy is an individual's confidence in the personal ability to complete a task under specified conditions. Game self-efficacy is the belief of game players that they would win in a business simulation game competition. To understand the composites of such belief, an instrument of 30 statements was developed and statistically tested on 227 undergraduate students atthe end of a business simulation game competition. The factor analysis produced eight factors of perceived game self-efficacy, namely, innovation, experimentation, conviction, openness, focus, proactivity, conceptualisation and determination. These factors have significant research implications for goal-oriented behaviour, goal setting and performance enhancement at work and in games and competitions, and in developing simulation games.
\end{abstract}

Keywords: business simulation; game self-efficacy; goal-oriented behaviour

(c) Sciendo

\section{INTRODUCTION}

The self-efficacy of individuals is instrumental in producing the deliberate or desired results of their efforts. Bandura $(1977,1997)$ expounded self-efficacy as 'one's belief in one's ability to succeed in specific situations or accomplish a task' and as 'the confidence in one's own ability to achieve intended results'. Making self-efficacy specific to a task and its situation recognised that human performance is affected by external issues like the nature of the task, the tools in use and the situation. Thus, self-efficacy is the belief in one's capabilities to act and produce desirable results from such actions.

As self-efficacy is the individuals' belief of their competence, Bandura (1995) proposed four sources of information for their beliefs: mastery experiences, vicarious experiences, social persuasion and physiological and emotional states. Mastery experiences emerge from their use of cognitive, behavioural and self-regulatory tools, and their perseverance in the face of adversity, that is, the repeated use of unique ways to solve personal problems in life, despite failures and hurdles. They could also learn from the experiences of others (vicarious), which encourage them to act and achieve something because others have done so. Their self-efficacy is affected by others' encouragement or discouragement (social persuasion), thus recognising peer pressure to be a psychological influence to reckon with. Finally, physiological and emotional states in the form of physical conditions (e.g., heat, dust, noise, aches and ambience) and psychological states (e.g., fear and stress) may encourage or discourage them about what and how well they could perform a specific task in a specific situation. Bandura's self-efficacy theory contrasts with Deci and Ryan's (2000) self-determination theory (SDT) in terms of the reasons for the individual's goal-directed behaviour. While self-efficacy is the belief of the individual in the ability to succeed, the SDT model proposed self-determination as the set of innate psychological needs of autonomy, competence and relatedness, which together produce the motivation for the behaviour towards the pursuit and achievement of goals. While autonomy (the desire to act voluntarily and independently) and competence (the ability to complete a task) are intrinsic drives, their extrinsic 
motivation produced relatedness (the desire for useful connections with others).

\section{Self-efficacy predicts performance}

Self-efficacy correlates positively and strongly with task significance, job satisfaction and organisational commitment (Jex and Bliese, 1999). In contrast with constructs such as outcome expectations, self-concept and perceived control, it is a multidimensional disposition (Zimmerman, 2000). It deals with the future and predicts students' effort, persistence, achievement, changes in performance in their studies, and emotional reactions. Mastery experiences, also known as enactive experiences or performance accomplishments, is the most influential source of self-efficacy, when compared to the other three sources identified by Bandura $(1977,1995)$. Jensen (2012) identified enactive mastery experiences in naturally occurring situations. In the growth experience, mastery grew from exposure to repeated experiences. In the interactive experience, mastery was generated from emotional, communicative and other actions performed jointly with others.

Self-efficacy predicted flow experience and academic engagement in a study of 346 Philippino and Argentinian undergraduate students (Mesurado et al., 2015). It develops from mastery and vicarious experiences through practice and exposure, as seen from the experience of Korean undergraduates who had stayed abroad in English speaking countries (Kim and Cha, 2017). Their English language learning self-efficacies, as self-perceived abilities, in the use and comprehension of English, grew due to their immersion and regular exposure to the English language environment in the foreign country. Oliveira et al. (2018) used a perceived self-efficacy scale composed of three factors, namely, academic success, self-regulated learning and extracurricular activities, to show that each factor correlated with their academic achievement and career exploration.

\section{Self-efficacy produces goal-oriented behaviour}

Individuals with high self-efficacy behave differently from those with low self-efficacy. Employees with high general self-efficacy and felt responsibility are more likely to take charge and create change in the workplace (Morrison and Phelps, 1999). High self-efficacy individuals are more committed to their teams, are more satisfied with high significance tasks, and experience less stress despite difficult tasks, especially when the team's collective efficacy is high. They are far less likely to be influenced by external advice or inputs than those with low self-efficacy, especially when the domain task is more difficult (Lucas et al., 2006). Students with high self-efficacy were more engaged in their studies, earned better grades, and had higher academic ambitions than others (Bassi et al., 2007). They approached their homework and other learning tasks with a high level of optimal experience that was characterised by clear goals, feedback, high perceived challenges matched by their skills, involvement and concentration.

Entrepreneurs had high self-efficacy due to their convictions that their goals were achievable and because their perceived mastery over their competence and actions was driven by their economic self-interest and their openness to feedback and change (Brandle et al., 2008). Employees' self-efficacy is positively associated with their performance (Tim et al., 2014). A mixed-methods study showed that the direct experience of mastery was the only predictor of self-efficacy (Usher et al., 2019). Although both success and failure affected the girls' confidence, they were affected more than boys by their negative experiences. Girls reported more vicarious experience than boys in math, while boys experienced more self-efficacy in science than girls.

\section{Belief is central to self-efficacy}

A person's belief is an indispensable input into one's thoughts and actions. The meanings of knowledge and beliefs overlap so much that it is very difficult to distinguish one from the other (Pajares, 1992). It is not easy to define beliefs clearly, which have many synonyms such as attitudes, judgements, values, perceptions, dispositions, preconceptions and perspectives. Beliefs begin to form very early in the life of individuals and therefore develop as a product of their reasoning and experiences. However, they are rarely affected by events or logic, later in their lives. Their belief systems help them to understand and cope with external events, and their beliefs help them interpret their knowledge and shape their perceptions and behaviours, including their choice of tasks and tools. Attitudes and beliefs lead to actions, including information-processing and participation in change. Beliefs are 'psychologically held understandings, premises or propositions' of the world (Richardson, 1996, p. 104), as accepted to be true by them. They are the results of their past experiences and are difficult to change.

The individual's mindset is the belief that personal characteristics such as intelligence, creativity, assumptions, perceptions or philosophy can be changed (Dweck, 2006). This belief guides every aspect of a person's life, including efforts, failures and successes, in terms of two different mindsets. The fixed mindset is the individual's conviction 
that personal characteristics cannot change; the growth mindset is the conviction that one is sure to learn or acquire new abilities and apply them. The growth mindset produces perseverance and resilience from the conviction that individuals can enhance their abilities using personal characteristics, life situations and external conditions. Beliefs satisfy important psychological and functional needs of the individual. They are visible in the form of confidence in one's abilities, moral self-esteem, hope and anxiety reduction, social identity, political ideology and religious faith (Bénabou and Tirole, 2016). They tend to be choices between accuracy and desirability and depend on affective and functional motives that are based on the selective denial of reality, self-deception, irrational perspectives and misinterpreted information to suit the individual's self-image. Consumer decisions are driven by beliefs that affect their behaviours in choice and purchase. High-priced products gain from their beliefs about quality (a measure of product features) and cheaper goods gain from their beliefs about taste (a measure of buyers' preferences) (Spiller and Belogolova, 2017).

\section{Simulation games}

A game is a world of fantasy in which its players tackle the challenges and unpredictable situations within. They feel the urge to accomplish the goal by outsmarting and overcoming their adversaries, who are other players in the same game. Their behaviour is constrained by rules that define the game and is shaped by feedback about their own and their competitors' progress (Garris et al., 2002). Game players may experience a psychological state of consciousness called flow, where they can become so engrossed in their actions that they can lose sense of time (Csikszentmihalyi, 1990). Such games have clear goals (winning objectives) and challenging problems that are a match for their skills. The players receive immediate and regular feedback on their progress, which enhances their absorption in the game, helps them to learn, adapts their behaviour, and builds their confidence to use their abilities to solve game problems. In a study of 83 students engaged in nine creativity games, the flow experience in the period of their deep engagement with their games, due to the challenge therein, influenced their mastery experience and self-efficacy, and their self-efficacy influenced their mastery experience (Yeh et al., 2019).

Tompson and Dass (2000) showed that the self-efficacy among 252 undergraduates in the enterprise simulation of their strategic management programme was enhanced due to their participation in the game. The business strategy game is a learning experience that develops the players' self-regulatory skills, such as the ability to make and assess decisions, set goals and persist with action, despite difficulties. Self-efficacy built their convictions to deal with uncertainty, chaos and randomness, strengthened their resolve to act, and produced desired results. A simulation represents an event whereas a game is an artificial activity with a context, goal and rules that create a competitive platform for its players (Wilson et al., 2009). Thus, the closed and controlled environment of the business simulation game offers an excellent space for the study of the players' self-efficacy in a business context.

\section{Objectives of the study}

Perceived self-efficacy is the belief of an individual that predicts intention to complete a specific task. The foregoing review of the literature has shown that belief has many meanings, such as attitude and perception. The composites of perceived self-efficacy of players in any game were not found in the literature. The present study was conducted to understand the construct of perceived game self-efficacy of players in a competitive business simulation game with the following objectives:

1. To extract and understand the factors of the construct of perceived game self-efficacy under such conditions.

2. To determine the relationship between the factors of perceived game self-efficacy, in terms of their correlations between them and their effects on each other.

3. To propose new research about perceived game self-efficacy and its factors, based on the findings of the study.

4. To recommend the application of perceived game self-efficacy and its factors in games, learning, business and other domains.

\section{METHOD}

\section{The simulation game process}

The study was conducted in a management school in Coimbatore, India, in a business game called IceBreaker, an enterprise simulation designed by the first author. The game was chosen for this study because it offered a business context in a competitive environment of interactions among players who would exhibit self-efficacy in their goal- 
oriented game behaviour. Both authors had a cumulative experience of almost 40 years in the design, development and facilitation of simulation games, and more than 70 years in teaching, instructional design, research, training, assessment, administration and other management education functions. The first author created the basic frame of the game in 2003 and since then has facilitated it for more than 12,000 learners of different disciplines. The authors understood it better than any other game, as they were aware of its processes, features and benefits. Thus, they knew that they would be able to control the gameplay as desired, and design appropriate statements in the instrument used in the study.

The game was conducted as an all-day competition between teams of four students each. A set of 10 teams made and sold products in a dynamic, simulated economy. Before the game, each player received a game manual of terminology, instructions and examples, to enable them to play the game. The first author facilitated the game and guided the teams by explaining the game rules, team behaviour, deadlines and results. Each team managed its respective firm for six months of business operations in two stages of three months each. Students received reading material about business issues that kept them focused on the game. Team-specific financial reports at the end of each stage enabled them to know the relative positions of other teams. The competition awarded prizes to the students of the winning teams.

\section{The game players}

The participants in the competition were students in the final year of different colleges in Coimbatore, India. They were enrolled in degree courses in commerce (46\%), engineering (30\%), business administration (16\%) and other disciplines (8\%) after 14 years of schooling. The youngest and oldest students were 18 years and 23 years old, respectively. The mean age of the respondents was 19.94 years, with a standard deviation of 1.01 years. Of the final sample of 227 respondents, $52 \%$ were male students and $48 \%$ were female students. Before the game began, students formed teams with their classmates and registered for the competition as teams of four members each.

\section{The instrument}

The self-efficacy instrument was described with keywords that affected or described a player's expected behaviour in the game, such as plan, action, confidence, problems, progress, winning, discourage, unforeseen, rules, challenge, failure and victory. First, the authors made a list of 40 statements from these keywords, based on their deep exposure to simulation games. Next, it was scrutinised for representativeness of beliefs and efforts (key aspects and descriptors of perceived game self-efficacy), redundancy and lack of clarity. This exercise ensured the face validity of the statements in the instrument and confirmed that the statements collectively represented the perceived game self-efficacy of the players in a simulation game. Many statements were shortened and recast for quick responses. Finally, the list was pruned down to 30 statements, so that the short instrument would facilitate quick responses at the end of the competition. As players in the game, the students made business decisions, analysed business results, and were immersed in learning under competitive conditions. The game environment developed their self-efficacy and primed them emotionally to respond to the statements in the instrument. The instrument was administered to the students after the results were declared at the end of the game, ensuring that their game experience affected their responses.

\section{Data analysis}

The data were subjected to exploratory factor analysis (EFA), using SPSS 21.0. The EFA is a method of abductive reasoning that reduces data which was descriptive, appropriate and relevant to perceived game self-efficacy as the phenomenon under study (Haig, 2005, 2008). The EFA produces factors as condensed products of the statements which together represent perceived game self-efficacy. The factor names represent the keywords in the statements and give due consideration to repeated and similar keywords and their loadings within the factor. This paper describes and discusses each factor from different angles and offers the most balanced and meaningful interpretation of the findings. 


\section{RESULTS}

The instrument was administered to 248 students in 62 teams in the game. Complete and correct responses, without any outlier data, were received from only 227 students, that is, $92 \%$ of the participants. The corrected item-total correlation figures were examined and none were found to be insignificant. The SPSS outputs refer to the statements of the instrument as items. The 30 items were then subjected to EFA under principal component analysis with varimax rotation. Eight factors, each of eigenvalue more than one and cumulatively explaining $54 \%$ of the variance, were extracted (Table 1).

Table 1. Perceived game self-efficacy: Statements, factors and loadings

Factors and loadings

\begin{tabular}{llllllll} 
Items*, $n=227$ & 1 & 2 & 3 & 4 & 5 & 6 \\
\hline \hline
\end{tabular}

\section{Factor 1: Innovation}

Unusual methods as a winner

Confidence to win

Easy to beat the competition

Explore with untried actions

Use numbers and diagrams

\section{Factor 2: Experimentation}

Experiment with new methods $\quad .72$

Remain focused on winning $\quad .58$

Practice different approaches $\quad .53$

Do not feel bad if proved wrong $\quad .48$

Plan ahead $\quad .45$

Asking why and how $\quad .38$

Factor 3: Conviction

Confidence to face challenges

Learn from my mistakes

Track my progress

Solve problems

Think harder to win

\section{Factor 4: Openness}

$\begin{array}{ll}\text { Useful ideas from discussion } & .70\end{array}$

I listen to my team mates $\quad .61$

Get consent of team mates $\quad .55$

Understand game rules $\quad .48$

\section{Factor 5: Focus}

Work harder to win

Mix different kinds of information $\quad .50$ 


\begin{tabular}{|c|c|c|c|c|c|c|c|c|}
\hline Items* ${ }^{*}, \mathrm{n}=227$ & 1 & 2 & 3 & 4 & 5 & 6 & 7 & 8 \\
\hline \multicolumn{9}{|l|}{ Factor 6: Proactivity } \\
\hline Watch my competitors & & & & & & .70 & & \\
\hline Respond to unforeseen & & & & & & .61 & & \\
\hline Do not give up in case of failure & & & & & & .50 & & \\
\hline \multicolumn{9}{|l|}{ Factor 7: Conceptualisation } \\
\hline Read about games & & & & & & & .71 & \\
\hline \multicolumn{9}{|l|}{ Factor 8: Determination } \\
\hline Errors do not discourage & & & & & & & & .78 \\
\hline Losing does not discourage & & & & & & & & .49 \\
\hline Help team mates for victory & & & & & & & & -.36 \\
\hline Internal consistency (Cronbach $\alpha$ ) & .68 & .69 & .67 & .58 & .55 & .51 & N.A. & .36 \\
\hline Eigen values & 2.68 & 2.62 & 2.29 & 2.27 & 2.01 & 1.76 & 1.43 & 1.40 \\
\hline Percentage of total variance & 8.94 & 8.72 & 7.63 & 7.58 & 6.71 & 5.85 & 4.77 & 4.65 \\
\hline
\end{tabular}

* abbreviated statements. N.A. = not applicable, as this factor had only one statement.

The rotation converged in nine iterations. The Kaiser-Meyer-Olkin measure of sampling adequacy of .83, at a significance of .00 , was above the recommended value of .6 and confirmed the adequacy of the sample size and the correlations between the items. Bartlett's test of sphericity was significant $\left(X^{2}(435)=1610.44, p<0.001\right)$. The study was deemed reliable due to the high value of Cronbach a of .86, as compared to the figure of .70, which is the accepted figure for social science research. This high figure suggests that the scale of 30 statements has high internal consistency.

After their respective statements had been scrutinised, the eight factors were named, in decreasing order of their eigenvalues, as innovation, experimentation, conviction, openness, focus, proactivity, conceptualisation, and determination, with the loading of each factor ranging from about $9 \%$ to more than $4 \%$, respectively. The Pearson correlation analysis between the factors showed positive correlations, out of which 22 were statistically significant ( $r$ $=>.14<.53, p<.01$ ) (Table 2). The correlations of conceptualisation with conviction, openness and determination $(r=.11, .07$, and $.08, p=n . s$. $)$ were not significant.

Table 2. Perceived game self-efficacy: Inter-factor correlations

\begin{tabular}{|c|c|c|c|c|c|c|c|c|c|}
\hline Factors & M & SD & 1 & 2 & 3 & 4 & 5 & 6 & 7 \\
\hline Innovation & 2.63 & .67 & & & & & & & \\
\hline Experimentation & 2.98 & .58 & $.45^{* *}$ & & & & & & \\
\hline Conviction & 3.00 & .58 & $.31^{* *}$ & $.52^{\star *}$ & & & & & \\
\hline Openness & 3.20 & .57 & $.20^{* *}$ & $.40^{* *}$ & $.46^{* *}$ & & & & \\
\hline Focus & 3.06 & .61 & $.32^{* *}$ & $.50^{* *}$ & $.38^{* *}$ & $.27^{\star *}$ & & & \\
\hline Proactivity & 2.96 & .65 & $.26^{* *}$ & $.37^{\star *}$ & $.44^{* *}$ & $.33^{\star *}$ & $.21^{* *}$ & & \\
\hline Conceptualisation & 2.58 & .95 & $.29^{* *}$ & $.19^{* *}$ & .11 & .07 & $.16^{*}$ & $.13^{*}$ & \\
\hline Determination & 3.20 & .55 & $.14^{*}$ & $.44^{* *}$ & $.41^{* *}$ & $.40^{* *}$ & $.47^{\star *}$ & $.22^{* *}$ & .08 \\
\hline
\end{tabular}

**. significant at the 0.01 level (2-tailed). *. significant at the 0.05 level (2-tailed).

The regression results paralleled most of the correlations, and thus, confirmed the accuracy of the relationships 
between such factors (Table 3). Experimentation affected six of the other seven factors, while conceptualisation affected only innovation $\left(.15^{* *}\right)$. Eight pairs of factors affected each other, of which the strongest predictor effects were seen within the innovation-experimentation $\left(.21^{* *}\right.$ and $\left..48^{* *}\right)$, experimentation-focus $\left(.31^{* *}\right.$ and $\left..21^{\star \star}\right)$, and conceptualisation-innovation $\left(.41^{* \star}\right.$ and $\left..15^{\star *}\right)$ pairs.

Table 3. Perceived game self-efficacy: Inter-factor regression coefficients

\begin{tabular}{|c|c|c|c|c|c|c|c|c|c|}
\hline $\begin{array}{l}\text { Factor / dependent } \\
\text { variable }\end{array}$ & Constant & 1 & 2 & 3 & 4 & 5 & 6 & 7 & 8 \\
\hline Innovation & .84 & & $.48^{\star \star}$ & & & & & $.15^{\star \star}$ & \\
\hline Experimentation & .16 & $.21^{\star \star}$ & & $.23^{\star *}$ & & $.21 \star \star$ & $.11^{*}$ & & $.19^{\star \star}$ \\
\hline Conviction & .36 & & $.28^{\star \star}$ & & $.21^{\star \star}$ & & $.21 * \star$ & & $.16^{\star}$ \\
\hline Openness & 1.18 & & $.16^{\star}$ & $.28^{* *}$ & & & & & $.22^{\star \star}$ \\
\hline Focus & .65 & $.13^{*}$ & $.31^{* *}$ & & & & & & $.35^{\star *}$ \\
\hline Proactivity & 1.16 & & $.22^{\star \star}$ & $.38^{* *}$ & & & & & \\
\hline Conceptualisation & 1.51 & $.41^{\star *}$ & & & & & & & \\
\hline Determination & 1.07 & & $.18^{\star \star}$ & & $.24^{\star \star}$ & $.27^{\star \star}$ & & & \\
\hline
\end{tabular}

**. significant at the 0.01 level (2-tailed). ${ }^{*}$. significant at the 0.05 level (2-tailed).

\section{DISCUSSION}

The EFA showed perceived game self-efficacy to be a multidimensional construct of eight factors (Table 1), with some having huge potential to correlate with (Table 2) and affect each other (Table 3). The results in the tables and the statements in the study instrument explained Bandura's (1977) self-efficacy and related research constructs and findings of the past. The factors together comprise the construct of perceived game self-efficacy of students in a business simulation game (Figure 1). The nature of each factor is first examined below, along with the relationships and effects, followed by the contributions of the study.

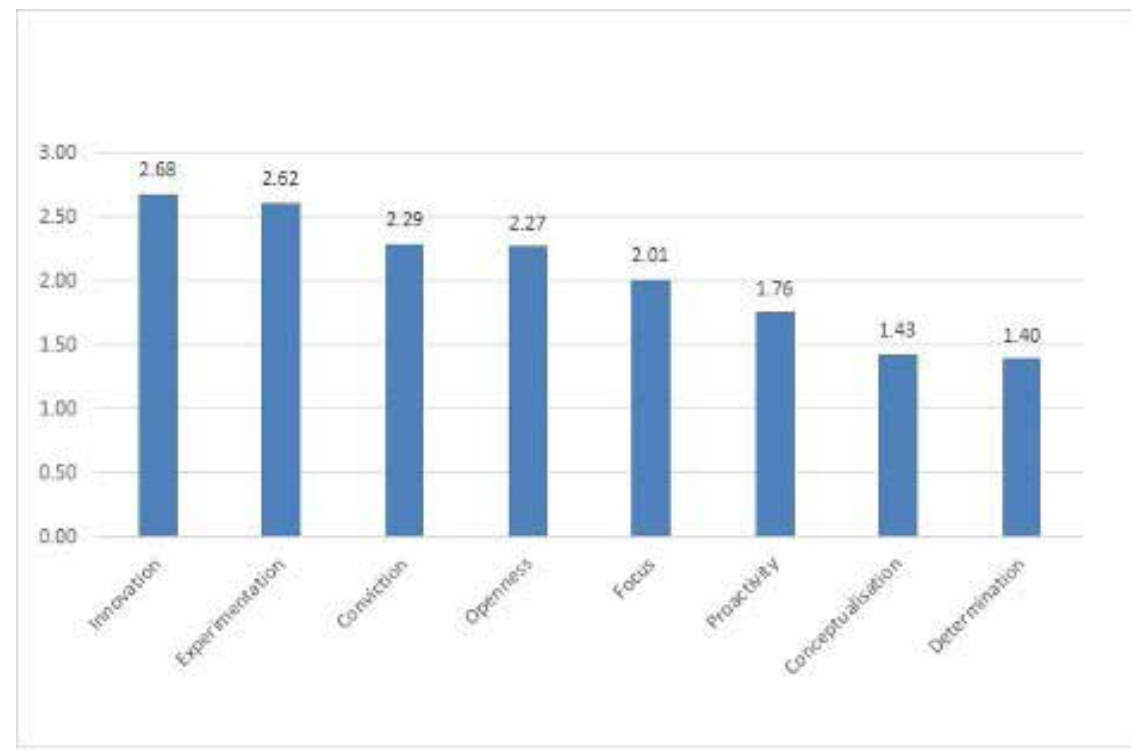

Figure 1: Perceived game self-efficacy factors ( $x$-axis) and their respective eigenvalues ( $y$-axis) 
Innovation is a set of unusual methods and untried actions (Goepel et al., 2012; Steel et al., 2012) to produce unexpected results that comprise one's mastery experience (Bandura, 1995). It was a product of experimentation $\left(.48^{* *}\right)$ and conceptualisation $\left(.15^{* *}\right)$ in the game and used game processes that would lead to victory.

Experimentation is driven by curiosity and clarifies doubts, confirms hypotheses, and enhances mastery experience, despite error and failure (Phillips, 2015). It was produced from the collective effect of five factors, namely, innovation $\left(.21^{* *}\right)$, conviction $\left(.23^{* *}\right)$, focus $\left(.21^{* *}\right)$, proactivity $\left(.11^{*}\right)$ and determination $\left(.19^{* *}\right)$. It had the lowest regression constant (.16) in the game, which suggested that it could be produced only after considerable effort.

Innovation and experimentation correlated strongly $\left(.45^{* *}\right)$, but their source statements were different. Neither was affected by openness in the game because the players may not have had sufficient time to use their curiosity, interest and imagination, and convert their observations into useful action in the game. The regression analysis showed that seven factors acting together affected both innovation and experimentation in the game, to enhance their mastery experience (Bandura, 1995).

Facing challenges and solving problems developed conviction (Judge et al., 2000) and enhanced the mastery experience (Bandura, 1995). The combined effect of four factors, namely, experimentation $\left(.28^{* *}\right)$, openness $\left(.21^{* *}\right)$, proactivity $\left(.21^{*}\right)$ and determination $\left(.16^{* *}\right)$, along with the low regression constant $(.36)$ in the game, showed that conviction could not be generated easily.

Openness is an expression of curiosity and was seen in the players' willingness to listen to their colleagues in the team and learn and receive new ideas from them (Gjerde and Cardilla, 2009; John and Srivastava, 1999; Lachman and Weaver, 1997). It enhanced their vicarious experience (Bandura, 1995) and was produced from the joint effect of experimentation $\left(.16^{*}\right)$, conviction $\left(.28^{* *}\right)$ and determination $\left(.22^{* *}\right)$. The high regression constant (1.18) showed that openness was easy to practice and may have been a product of the discussions and interactions between team members.

Focus produced wins due to the curiosity about and the selective attention to specific tasks (Bishop et al., 2004; Fougnie, 2008) and could be the basis of both mastery and vicarious experiences (Bandura, 1995). It was created in an environment of innovation $\left(.13^{* *}\right)$, experimentation $\left(.31^{* *}\right)$ and determination $\left(.35^{\star *}\right)$, but its low regression constant (.65) showed that it was not easy to be focused.

Proactivity is a goal-driven behaviour (Parker et al., 2010, 2017) that produced wins due to the curiosity about, and attention to, specific tasks, and could be a reaction to both social persuasion and the external physiological and emotional environment of the game (Bandura, 1995). Its high regression constant (1.16) showed that it was easily formed due to the players' experimentation $\left(.16^{*}\right)$ and conviction $\left(.28^{* *}\right)$ in the game.

Conceptualisation is a product of experiences from one's actions and observations of others' actions, that is, mastery and vicarious experiences (Bandura, 1995). In the game, it was influenced only by innovation (.41**). It had the largest regression constant (1.51), suggesting that having a keen understanding of the game environment (Podsakoff et al., 2016) was the major precondition of, and contributor to, successful game outcomes.

Determination was a product of three variables, experimentation $\left(.18^{*}\right)$, openness $\left(.24^{* *}\right)$ and focus $\left(.27^{* *}\right)$. It is a sign of resilience, that is, the ability to withstand the discouraging effects of errors and losses in the game. It can lead to perseverance (Duckworth et al., 2007) and can be the driving force to produce goal-focused behaviour (Deci and Ryan, 2000).

\section{Contribution of the factors of perceived game self-efficacy}

Innovation. Innovation is the product of an individual's imagination and efforts. It is the individual's propensity to intentionally introduce or apply a novelty that had social ramifications and the intention of benefit (Goepel et al., 2012). The innovator creates an idea and converts it into a useful product of economic value (Steel et al., 2012). Innovation is a complex social process that can be deemed a success only when the novel product is accepted in the marketplace. Openness to experience and agreeableness, two Big Five personality factors, affect innovation significantly. Innovation will flourish in societies that allow curiosity (about experiences, new concepts, and others' beliefs) and trusting behaviour. Innovation is the evolution of almost anything novel that can produce some useful social or other benefits (Dougherty and Clarke, 2018). Successful innovators have traits such as curiosity, creativity and the courage to experiment and to take risks, and are imaginative, observant and ready for action.

Experimentation. An experiment is an act of discovering what may have been unknown before, to test the effectiveness of a product, or to validate a theory or hypothesis. Experimentation is a vital process in innovation, which converts ideas and concepts into useful products or builds insights about the processes. The experimenters 
are driven by curiosity and attention to the things that they care about, and which is best seen in the form of visual attention, questions and debates (Phillips, 2015).

Conviction. Conviction is a belief, an attitude and confidence acquired from past mistakes, tracking progress and solving problems, and produces the tenacity and readiness to face and conquer challenges. Highly confident individuals may seek out more difficult tasks than others (Judge et al., 2000). Academic confidence is the strength of students' belief, trust or expectation with respect to their university offerings and opportunities (Sander and Sanders, 2003). Confidence is a blend of the individuals' assessment of being correct, their belief about what they can do, and their likelihood to act, showing it to be a composite of their cognitive, personality and motivational aspects (Stankov et al., 2014). Tucket and Nikolic (2017) pointed out that such conviction is a mix of knowledge, beliefs, causal models and rules of thumb, which enables people to identify opportunities for action and prepares them for environments of radical uncertainty.

Openness. Openness to experience is a Big Five trait whose facets include curiosity, imaginativeness, aesthetics, wide interests, feelings and unconventionality (John and Srivastava, 1999). Lachman and Weaver (1997) extracted factors of openness to experience which they named as creative, imaginative, intelligent, curious, broadminded, sophisticated and adventurous. Gjerde and Cardilla (2009) found that openness predicts imaginativeness and shared meaning with intelligence. An individual with openness to experience is willing and eager to savour novel experiences and exposure to new ideas, emotions and events (McCrae and Greenberg, 2014). The trait of openness to experience has six facets, namely, openness to fantasy, aesthetics, feelings, actions, ideas and values, and demonstrates a strong urge to learn, change and imbibe new behaviour. Openness is strongly associated with mixed emotions, such as being happy and sad (Barford and Smillie, 2016).

Focus. Attention is behaviour that allows a person to select from the environment a limited amount of information and to process it selectively (Fougnie, 2008). It is a matter of interest where one can control personal experiences by selecting from the range of issues to focus on (Wadlinger and Isaacowitz, 2011). Meditative practice and concentration are examples of attentional processes that produce better emotional responses. Being the final step in the attention process, focus produces superior performances with more information and experiments. Bishop et al. (2004) concluded mindfulness to be a meta-cognitive skill and a psychological process of self-observation and deep awareness, to gain insight to regulate one's mind, mood and behaviour. They proposed mindfulness to be a model of two components, the self-regulation of attention (described as a deep awareness and experience of the present) and the orientation to experience (described in terms of curiosity, openness and acceptance).

Mindfulness produces a kind of meta-cognitive feeling called 'fringe consciousness', a perception beyond the individual's immediate scope of sensory observation that can enlarge their awareness beyond this consciousness (Norman, 2016). It predicts self-efficacy and produces better self-control and attention to problems (Tang et al., 2019). It is a state of sharp focus on the present moment, without being distracted by the effects of memory, experience or judgement. Thus, attention, mindfulness, and focus are different forms of generating acute awareness of, and engagement in, the present moment, without distractions for the sole purpose of getting better results.

Proactivity. Being proactive is about planning for and taking the steps to achieve goals. Making things happen, anticipating and preventing problems, and seizing opportunities were proactive actions (Parker et al., 2010). An individual's proactive behaviour stemmed from motivational states such as perceptions of self-efficacy, intrinsic sources and positive affective states, and individual differences such as personality and value systems, and external influences such as interpersonal climate. Proactivity was one of the five factors of interpersonal competitiveness in a scale tested on a sample of 379 business management students who played a one-day business simulation game similar to that played by the respondents of this study (Dumblekar, 2010).

Proactive employees were more outspoken than others, thus building trust with colleagues and creating a conducive and nurturing atmosphere for creativity (Gong et al., 2012). Proactive individuals are dependent on others, due to collectivistic and high-power distance culture, and are therefore creative only after complying with social norms. Proactivity is seen in the future-focused, change-oriented and self-starting actions of the individual (Parker et al., 2017). It is a goal-driven behaviour that begins without any direction or prompting from others and is an intrepid action that creates beneficial and positive change by accomplishing the goal.

Conceptualisation. Conceptualisation is the result of observations and analyses of actions and is the basis for learning experiences that produce knowledge from experimentation and innovation. Such experiences lead to abstract concepts as broad conclusions that are then put into action or tested to produce new experiences (Kolb, 1984). No player can win without a conceptual understanding of the game, which is a system of players (including competitors), game resources, winning criteria and measures, playing constraints and rules. This cognitive view may 
be a framework of components, situations and processes that can be depicted by diagrams to capture relationships, incompatibilities and overlapping meanings (Barki and Hartwick, 2004).

The understanding of conceptualisation is enhanced by Fawcett's (2012, p. 285) definition of a concept as 'a label, expressed as a word or phrase, that summarises the essence of a phenomenon', whether abstract or otherwise, and of concept analysis as 'a technique used to identify the attributes, properties, or dimensions of a concept'. Podsakoff et al. (2016, p. 161) defined concepts as 'cognitive symbols (or abstract terms) that specify the features, attributes, or characteristics of the phenomenon in the real or phenomenological world that they are meant to represent and distinguish them from other related phenomena'. Only a player with a conceptual view of game features such as regulations, deadlines and scoring procedures could have a winning edge over others who do not.

Determination. Duckworth et al. (2007) defined grit as perseverance and passion for long-term goals which represented the determined efforts to overcome challenges, despite distractions, hurdles, delays and other adversities. Later, Duckworth and Gross (2014) reiterated that the persistent and determined pursuit of difficult goals is the key ingredient of extraordinary success. Deliberate and focused practice and harmonious passion are the key inputs in such determination. Kirby et al. (2014) suggested that challenge is a positive motivational state that was directed at tackling goals and is similar to expressions such as determination, persistence, and motivation. It correlated with task engagement, high problem-focused coping potential and confidence.-

The regression results showed that understanding the essence of the game is the most important prerequisite element of perceived game self-efficacy, as shown by the high regression constant (1.51) for conceptualisation. Additionally, the winners of a game needed the attitude and ability (Deci and Ryan, 2000) to receive ideas and other inputs and act pre-emptively, as suggested by the other high constants for openness (1.18) and proactivity (1.16). Conceptual knowledge of the game helps them to produce experimentation, which is the most pervasive and powerful self-efficacy factor because of its vast potential to affect six other factors, such as innovation and conviction (Table 3).

\section{CONCLUSION}

This study produced an instrument to examine the construct of perceived game self-efficacy. Eight factors, namely, innovation, experimentation, conviction, openness, focus, proactivity, conceptualisation and determination were extracted from 227 responses to a 30-statement instrument from undergraduate students in a business simulation game. The factors and their correlations and regressions were further examined in terms of their elements and outcomes. Conceptualisation offers the maximum contribution to the construct and experimentation is the allpervasive factor that predicts almost all other factors. In contrast with the belief-centric concept of Bandura's (1977) self-efficacy, perceived game self-efficacy is a composite of potential actions (innovation, experimentation, focus, and conceptualisation), personality traits (openness, proactivity, and determination) and belief (conviction).

\section{Implications for further research}

This research offers new insights into perceived game self-efficacy and its factors. Self-efficacy, self-determination (Deci and Ryan, 2000) and grit (Duckworth et al., 2007) produce goal-oriented behaviour. It would be interesting to ascertain how the three constructs and their elements correlate with and predict one another under common conditions. Would self-determination correlate with determination? Could persistence predict determination? And, how would autonomy and competence affect innovation, experimentation and proactivity? The appropriate platform for the research could be a simulation game in the context of a business environment of scenarios, problems and challenges.

The simulation game represented a manufacturing business environment and produced eight factors of perceived game self-efficacy, which characterised the environment and the expected behaviours of players as managers that produce optimal business results. Perceived game self-efficacy could shape the development of business games based on learning objectives and provide insights to students and teachers in business management education. There is a need to develop game self-efficacy scales with appropriate factors for other business game environments, such as services, trading, extraction and agriculture. Similarly, we need scales and factors for functional environments such as financial, marketing, human resource and project management. The discovery of self-efficacy in different domains of human activities would offer a deeper understanding of their processes for students, teachers and practitioners. The participants in the game were undergraduates; if the participants in other business or functional 
games were older, their work experience would be adequately captured in the research efforts.

This study was conducted in the context of a business simulation game in a competition. The development of similar scales in other games may help to select efficacious players. Games like cricket, football, basketball, tennis and baseball attract huge investment for their infrastructure, player training, branding and advertising, prize money and technologies in their professional competitions, and therefore need players with the right mindset of potential actions, traits and belief. To capture the unique context of any game in the research, it would be necessary to conduct player interviews and observe player behaviour, to ascertain the nature of the game and its competitiveness and to develop appropriate statements for the instruments.

An individual's propensity to innovate and take risks may develop with the successes and experience but may decline due to role overburden after middle age. Klassen and Chiu (2010) studied 1,430 teachers and found that their teaching self-efficacy (measured in terms of classroom management, instructional strategies and student engagement) grew with teaching experience, and then declined after about 23 years of experience. Thus, future research may attempt to discover self-efficacy factors that are affected by human characteristics such as gender and age.

The game self-efficacy factors offer vital clues to effective action in situations that demand timely completion (e.g., in surgeries, projects and sales campaigns) and victory (e.g., games and competitions). If the scale were customised for specific roles and environments, it could be used for testing, recruitment, roles and promotions in behavioural domains that need timely and effective task completion as formal management policy.

\section{Recommendations for application}

A competency is a clearly described behaviour driven by knowledge, skills, attitudes and traits that can lead to clearly defined and desired outcomes associated with a task, role or organisational need, and is therefore seen as vital in recruitment and selection, career development and performance management practices of organisations (Sparrow, 1995). The contributions of innovation, experimentation and proactivity were hitherto unreported in previous self-efficacy research. Management policy should ensure that employees be selected and trained for such competencies, so that employees use novel means to act, respond to problems before others do, remain undiscouraged by failure and embarrassment, are eager problem solvers and respond to challenges. Thus, game self-efficacy factors could be instrumental in selection, development and performance enhancement via goalsetting, training and coaching.

\section{ACKNOWLEDGEMENTS}

The authors acknowledge with appreciation the support extended by Professor S. Ganesan, Director, Firebird Institute of Research in Management, Coimbatore - 641021, INDIA.

\section{References}

Bandura, A. (1977). 'Self-efficacy: Toward a unifying theory of behavioural change'. Psychological Review, 84: 2, 191-215.

Bandura, A. (1995). 'Exercise of personal and collective efficacy in changing societies', in A. Bandura (ed.), Self-efficacy in Changing Societies, Cambridge, New York: Cambridge University Press.

Bandura, A. (1997). Self-efficacy: The Exercise of Control, New York: Freeman.

Barford, K.A. and Smillie, L.D. (2016). 'Openness and other Big Five traits in relation to dispositional mixed emotions'. Personality and Individual Differences, $102,118-122$.
Barki, H. and Hartwick, J. (2004). 'Conceptualizing the construct of interpersonal conflict'. International Journal of Conflict Management, 15: 3, 216-244.

Bassi, M., Steca, P., Fave, A.D. and Caprara, G.V. (2007). 'Academic self-efficacy beliefs and quality of experience in learning'. Journal of Youth and Adolescence, 36, 301-312.

Bénabou, R. and Tirole, J. (2016). 'Mindful economics: The production, consumption, and value of beliefs'. Journal of Economic Perspectives, 30: 3, 141-164.

Bishop, S.R., Lau, M., Shapiro, S., Carlson, L., Anderson, N.D., Carmody, J., Segal, Z.V., Abbey, S., Speca, M., Velting, D. and Devins, G. (2004). 
'Mindfulness: A proposed operational definition'. Clinical Psychology: Science and Practice, 11: 3, 230-241.

Brandle, L., Berger, E.S.C., Golla, S. and Kuckertz, A. (2008). 'I am what I am-How nascententrepreneurs' social identity affects entrepreneurial self-efficacy'. Journal of Business Venturing Insights, 9, 17-23.

Csikszentmihalyi, M. (1990). Flow: The Psychology of Optimal Experience. New York: Harper and Row, Publishers.

Deci, E.L. and Ryan, R.M. (2000). "The "What" and "Why" of goal pursuits: Human needs and the selfdetermination of behavior'. Psychological Inquiry, 11: 4, 227-268.

Dougherty, I. and Clarke, A. (2018). 'Wired for innovation: Valuing the unique innovation abilities of emerging adults'. Emerging Adulthood, 6: 5, 358-365.

Duckworth, A. and Gross, J.J. (2014). 'Self-control and grit: Related but separable determinants of success'. Current Directions in Psychological Science, 23: 5, 319-325.

Duckworth, A.L., Peterson, C., Matthews, M.D. and Kelly, D.R. (2007). 'Grit: Perseverance and passion for long-term goals'. Journal of Personality and Social Psychology, 9, 1087-1101.

Dumblekar, V. (2010). 'Interpersonal competitiveness A study of simulation game participants' behaviour'. Paradigm, XIV: 2, 13-19.

Dweck, C.S. (2006). Mindset: The New Psychology of Success, New York: Random House.

Fawcett, J. (2012). 'Thoughts on concept analysis: Multiple approaches, one result'. Nursing Science Quarterly, 25: 3, 285-287.

Fougnie, D. (2008). 'The relation between attention and working memory', in Noah B. Johansen (ed.), New Search on Short-term Memory, Hauppage: Nova Science Publishers.

Garris, R., Ahlers, R. and Driskell, J E. (2002). 'Games, motivation, and learning: A research and practice model'. Simulation and Gaming, 33: 4, 441-467.

Gjerde, P.F. and Cardilla, K. (2009). 'Developmental implications of openness to experience in preschool children: Gender differences in young adulthood developmental psychology'. American Psychological Association, 45: 5, 1455-1464.

Goepel, M., Hölzle, K. and Knyphausen-Aufseß, D. (2012). 'Individuals' innovation response behaviour: a framework of antecedents and opportunities for future research'. Creativity and Innovation Management, 21: 4, 412-426.

Gong, Y., Cheung, S-Y., Wang, M. and Huang, J-C. (2012). 'Unfolding the proactive process for creativity: Integration of the employee proactivity, information exchange, and psychological safety perspectives'. Journal of Management, 38: 5, 1611-1633.

Haig, B. D. (2005). 'An abduction theory of scientific method'. Psychological Methods, 10: 4, 371-388.

Haig, B. D. (2008). 'Scientific method, abduction, and clinical reasoning'. Journal of Clinical Psychology, 64: 9, 1013-18.

Jensen, R.E. (2012). Sex educators and selfefficacy: Toward a taxonomy of enactive mastery experiences. Health Education \& Behavior, 39: 3, 259-267.

Jex, S. M. and Bliese, P.D. (1999). 'Efficacy beliefs as a moderator of the impact of work-related stressors: A multi-level study'. Journal of Applied Psychology, 84: 3, 349-361.

John, O.P. and Srivastava, S. (1999). 'The Big-Five trait taxonomy: History, measurement, and theoretical perspectives', in L.A. Pervin and O.P. John (eds), Handbook of Personality: Theory and Research, vol. 2, New York: Guilford Press.

Judge, T.A., Bono, J.E. and Locke. E.A. (2000). 'Personality and job satisfaction: The mediating role of job characteristics'. Journal of Applied Psychology, 85, 237-249.

Kim, H. and Cha, K. (2017). 'Effects of experience abroad and language on self-efficacy beliefs in language learning'. Psychological Reports, 120: 4, 670-694.

Kirby, L.D., Morrow, J. and Yih, J. (2014). 'The challenge of challenge: Pursuing determination as an emotion', in M.M. Tugade, M.N. Shiota and L.D. Kirby (eds), Handbook of Positive Emotions, New York, NY: Guilford Press.

Klassen, R. and Chiu, M.M. (2010). 'Effects on teachers' self-efficacy and job satisfaction: Teacher gender, years of experience, and job stress'. Journal of Educational Psychology, 102: 3, 741-756.

Kolb, D.A. (1984). Experiential Learning: Experience as the Source of Learning and Development, Englewood Cliffs, NJ: Prentice Hall.

Lachman, M. and Weaver, S. (1997). The Midlife Development Inventory (MIDI) Personality Scales: Scale Construction and Scoring, Waltham, MA: Brandeis University.

Lucas, T., Alexander, S., Firestone, I. and Baltes, B. (2006). 'Self-efficacy and independence from social influence: Discovery of an efficacy-difficulty effect'. Social Influence, 1: 1, 58-80.

McCrae, R.R. and Greenberg, D.M. (2014). 'Openness to experience', in D.K. Simonton (ed.), The Wiley Handbook of Genius, John Wiley and Sons, Ltd. DOI: 10. 1002/9781118367377.ch12 
Mesurado, B., Richaud, M.C. and Mateo, N.J. (2015). 'Engagement, flow, self-efficacy, and eustress of university students: A cross-national comparison between the Philippines and Argentina'. The Journal of Psychology, 150: 3, 281-299.

Morrison, E.W. and Phelps, C.C. (1999). 'Taking charge at work: Extrarole efforts to initiate workplace change'. Academy of Management Journal, 42: 4, 403-419.

Norman, E. (2016). 'Metacognition and mindfulness: The role of fringe consciousness'. Mindfulness, 8: 1. DOI 10.1007/s12671-016-0494-z

Oliveira, I.M., Taveira, M.C., Porfeli, E.J. and Grace, R.C. (2018). 'Confirmatory study of the multidimensional scales of perceived self-efficacy with children'. Universitas Psychologica, 17: 1, 1-12.

Pajares, M.F. (1992). 'Teachers' beliefs and educational research: Cleaning up a messy construct'. Review of Educational Research, 62, 307-332.

Parker, S.K., Bindl, U.K. and Strauss, K. (2010). 'Making things happen: A model of proactive motivation'. Journal of Management, 36, 827-856.

Parker, S.K. and Bindl, U.K. (2017). 'Proactivity at work: A big picture perspective on a construct that matters', in S.K. Parker and U.K. Bindl (eds), Proactivity at Work: Making Things Happen in Organisations, London, UK: Routledge.

Phillips, R. (2015). 'Curiosity: Care, virtue and pleasure in uncovering the new'. Theory, Culture and Society, 32: 3, 149-161.

Podsakoff, P.M., MacKenzie, S.B. and Podsakoff, N.P. (2016). 'Recommendations for creating better concept definitions in the organizational, behavioral, and social sciences'. Organizational Research Methods, 19: 2, 159-203.

Richardson, V. (1996). 'The role of attitudes and beliefs in learning to teach', in J. Sikula (ed.), Handbook of Research on Teacher Education, New York: MacMillan.

Sander, P. and Sanders, L. (2003). 'Measuring confidence in academic study: A summary report'. Electronic Journal of Research in Educational Psychology and Psychopedagogy, 1: 1, 1-17.

Sparrow, P. (1995). 'Organizational competencies: A valid approach for the future?'. International Journal of Selection and Assessment, 3: 3, 168-177.

Spiller, S.A. and Belogolova, L. (2017). 'On consumer beliefs about quality and taste'. Journal of
Consumer Research, 43, 970-991.

Stankov, L., Kleitman, S. and Jackson, S.A. (2014). 'Measures of the trait of confidence', in G.J. Boyle, D.H. Saklofske and G. Matthews (eds), Measures of Personality and Social Psychological Constructs, Massachusetts: Academic Press.

Steel, G.D., Rinne, T. and Fairweather, J. (2012). 'Personality, nations, and innovation: Relationships between personality traits and national innovation scores'. Cross-Cultural Research, 46: 1, 3-30.

Tang, N., Han, L., Yang, P., Zhao, Y. and Zhang, H. (2019). 'Are mindfulness and self-efficacy related to presenteeism among primary medical staff: A cross-sectional study'. International Journal of Nursing Sciences, 6, 182-186.

Tim, M., Bakker, A.B. and Derks, D. (2014). 'Daily job crafting and the self-efficacy-performance relationship'. Journal of Managerial Psychology, 29: 5, 490-507.

Tompson, G.H. and Dass, P. (2000). 'Improving students' self-efficacy in strategic management: The relative impact of cases and simulations'. Simulation and Gaming, 31: 1, 22-41.

Tucket, D. and Nikolic, M. (2017). 'The role of conviction and narrative in decision-making under radical uncertainty'. Theory and Psychology, 27: 4, 510523.

Usher, E., Ford, C., Li, C.R. and Weidner, B.L. (2019). 'Sources of math and science self-efficacy in rural Appalachia: A convergent mixed methods study'. Contemporary Educational Psychology, 57, 32-53.

Wadlinger, H.A. and Isaacowitz, D.M. (2011). 'Fixing our focus: Training attention to regulate emotion'. Personality and Social Psychology Review, 15: 1, 75-102.

Wilson, K.A., Bedwell, W.L., Lazzara, E.H., Salas, E. and Burke, C. S. (2009). 'Relationships between game attributes and learning outcomes: Review and research proposals'. Simulation and Gaming, 40: 2, 217-266.

Yeh, Y., Chen, S-Y., Rega, E.M. and Lin, C-S. (2019). 'Mindful learning experience facilitates mastery experience through heightened flow and selfefficacy in game-based creativity learning'. Frontiers in Psychology, 10: 1-12.

Zimmerman, B.J. (2000). 'Self-efficacy: An essential motive to learn'. Contemporary Educational Psychology, 25, 82-91. 